1 The ecological costs to females in a system with allied sexual coercion

2

3 Megan M. Wallen ${ }^{\mathrm{a}^{*}}$, Eric M. Patterson ${ }^{\mathrm{a}}$, Ewa Krzyszczyk ${ }^{\mathrm{a}}$, and Janet Mann ${ }^{\mathrm{a}, \mathrm{b}}$

4

$5 \quad$ aDepartment of Biology, Georgetown University, Washington D.C.

$6 \quad{ }^{b}$ Department of Psychology, Georgetown University, Washington D.C.

$7 \quad$ *Author for correspondence: M.M. Wallen, 406 Reiss Science Bldg., Georgetown

8 University, Washington D.C., 20057-1229, USA. Telephone: +1 202-684-7139. Fax: +1

9 202-687-5662. Email address: mmw89@georgetown.edu

10

11 Word Count: 6914

12

13

14

15

16

17

18

19

20

21

22

23 


\section{The ecological costs to females in a system with allied sexual coercion}

\section{ABSTRACT}

29 Sexual coercion results from extreme conflict over mating. As a male strategy to

30 overcome female resistance, coercion can impose fitness costs on females. Among

31 mammals, most cases involve single males or temporary coalitions, with allied

32 aggression towards females being rare. Among Shark Bay bottlenose dolphins

33 (Tursiops cf. aduncus), male alliances harass, guard, and consort with females to obtain

34 mating access, which has known physical costs to females. However, the behavioural

35 and ecological costs of sexual coercion to females remain largely unexplored. Given the

36 importance of individual differences in ranging and habitat use for dolphin foraging

37 ecology, social networks, and fitness, we hypothesised that male coercion also imposes

38 ecological costs on females. Using 25 years of longitudinal data, we examined how

39 adult male presence relates to female space use and found that females $(N=32)$

40 altered their ranging when associating with adult males, but also when cycling.

41 Additionally, females reduced use of their primary (preferred) habitat when with males,

42 but cycling had no effect. Ranging shifts were slightly greater for males than for females

43 when they were together, but only for females did this alter their spatial ecology. While it

44 is also possible that males follow fertile females, and/or that females move to avoid

45 males, the well-documented coercive mating system suggests that males, as part of

46 their coercive mating tactics, sequester females to areas that females would not 
47 otherwise occupy. Our results show that in a coercive mating system, males can alter

48 females' basic behavioural ecology, and suggest that males spatially sequester

49 individual females via allied consortships.

50

\section{KEYWORDS}

52

53 Sexual conflict, sexual coercion, habitat use, centroid, ranging, bottlenose dolphin,

54 mating system, Tursiops, spatial ecology

55

56 Word Count: 6914

57

58

59 Sexual coercion, an extreme example of sexual conflict, is defined as when

60 males, at some cost to females, direct "force" or the "threat of force" toward females to

61 increase their chances of mating when females are fertile, and to decrease females'

62 chances of mating with other males (Smuts and Smuts 1993). Coercion, an adaptive

63 male strategy to overcome female resistance to mating and monopolise breeding

64 opportunities, is an important force in sexual selection (Clutton-Brock and Parker 1995)

65 and can potentially even lead to divergence and speciation (Panhuis et al. 2001).

66 Furthermore, direct costs to females due to male sexual aggression can be severe and

67 include injury (Le Boeuf and Mesnick 1991; Hiruki et al. 1993), increased energy

68 expenditure (Watson et al. 1998), increased mortality (Réale et al. 1996), physiological

69 stress (Muller et al. 2007), and decreased reproductive success (Hiruki et al. 1993; 
70 Ojanguren and Magurran 2007; den Hollander and Gwynne 2009; Gay et al. 2009;

71 Rossi et al. 2010; Takahashi and Watanabe 2010). Nonetheless, because documenting

72 such fitness costs is challenging, particularly in wild, long-lived animals, some

73 researchers have examined the behavioural and ecological costs females experience

74 as a result of male coercion, which may or may not have consequences for fitness. For

75 example, studies documenting changes in movement and ranging (e.g. Grevy's zebra

76 Equus grevyi, Sundaresan et al. 2007), activity patterns (e.g. southern elephant seals

77 Mirounga leonina, Galimberti et al. 2000; mollies Poecilia spp., Heubel and Plath 2008;

78 humpback whales Megaptera novaengliae, Cartwright and Sullivan 2009; and guppies

79 Poecilia mexicana, Köhler et al. 2011), and sociality (e.g. guppies Poecilia reticulata,

80 Darden et al 2009; Darden and Watts 2012) suggest that male coercion influences

81 important aspects of female behavioural ecology and likely fitness. Yet among these

82 studies, few have examined the impact males have on female behaviour or fitness when

83 they act collectively, i.e., coalitionary or allied aggression, perhaps because outside of

84 humans (Rodseth and Novak 2009), some non-human primates (chimpanzees Pan

85 troglodytes: Watts 1998, Muller et al. 2009, Connor and Vollmer 2009; baboons Papio:

86 Noë 1992; spider monkeys Ateles: Link et al. 2009), and some bottlenose dolphin

87 (Tursiops spp.) populations (Connor et al. 1992a, Connor and Vollmer 2009), allied

88 males rarely direct aggression towards females.

$89 \quad$ In several long-term studies of bottlenose dolphins, researchers have

90 documented a sexually coercive mating system in which adult males form long-term,

91 stable alliances (Connor and Vollmer 2009) of variable size (Wells 1991; Connor et al.

92 2001; Owen et al 2002; Wiszniewski et al. 2012) that cooperate to consort and mate 
93 with individual, primarily cycling, females (Connor et al. 1992a; Smolker et al. 1992;

94 Connor et al. 1996). Consortships are typically initiated by aggressive herding

95 behaviours such as biting, hitting, chasing, and threat displays or captures, followed by

96 intermittent aggression throughout the consortship (Connor et al. 1992a; Connor and

97 Smolker 1996). Among Indian Ocean bottlenose dolphins (Tursiops cf. aduncus) in

98 Shark Bay, Australia, preliminary evidence suggests that allied males influence female

99 ecology. Previous work found that females spend more time in deeper water and less

100 time in shallow water when in consortships (Watson-Capps 2005). Although the benefits

101 or costs of this shift are not fully understood, changes in depth use suggest that male

102 coercion may impact female spatial ecology.

103 Shark Bay dolphin spatial ecology has been previously described in some detail.

104 Individuals exhibit bisexual philopatry and have large, overlapping home ranges that are

105 stable through time (Tsai and Mann 2013). Habitat use is influenced by both predator

106 (tiger shark, Galeocerdo cuvier) and prey distributions on large and small spatial scales

107 (Heithaus and Dill 2002; 2006), meaning even small shifts in space use could have

108 potentially serious ecological outcomes for dolphins. However, such shifts likely have

109 the greatest impact on female ecology given that females exhibit habitat specific

110 foraging specialisations (Sargeant et al. 2007, Mann and Sargeant 2003; Sargeant et al.

111 2005; Mann et al. 2008; 2012), have smaller home ranges, and lower habitat use

112 diversity compared to males (Patterson 2012). For example, some females specialise in

113 a foraging tactic known as sponging, which involves the use of marine sponges as tools

114 and only occurs in the deep channels where sponges and appropriate prey are found

115 (Mann et al. 2008; Sargeant et al. 2007; Patterson and Mann 2011). Sponger females 
116 could be severely impacted if consorting males move them away from the channel

117 habitat. In contrast, individual males and alliances have much larger home ranges and

118 greater habitat use diversity (Randić et al. 2012; Patterson 2012), which likely relates to

119 their need to roam the bay to find and maintain access to fertile females. Thus, not only

120 is efficient space use inherently important for survival, but the observed variation among

121 individuals and among sexes is an explicit representation of individual ecological needs.

122 When considering that male and female space use must coalesce during

123 consortships, three scenarios are possible. First, it may be that males spatially

124 sequester females by consorting with them in accordance with their alliance's space

125 use. Here one would expect substantial ecological costs to females, and no such costs

126 to males. Second, it may be that males spatially sequester females to some extent, but

127 also partially adjust their alliance's space use to temporarily match that of fertile

128 females. Here one would expect ecological costs to both sexes, the magnitude of which

129 would depend on the relative space use shifts for each sex. Finally, it may be that males

130 do not spatially sequester females and instead temporarily adjust their alliance's space

131 use to match that of their targeted mate's range, i.e., males go where the fertile females

132 are and follow them around. Here one would expect males, but not females, to suffer an

133 ecological cost.

134 Given the aggressive nature of consortships, the first or second scenario, both of

135 which impose some ecological costs on females, seem most likely. Thus, we

136 hypothesise that males present an ecological cost to adult females by altering female

137 space use, specifically, their ranging and habitat use. If alliances sequester females to

138 their own, much larger home ranges, females will likely be far from their core home 
139 range area and their preferred foraging habitats. Accordingly, we predict that (1)

140 females will be farther from their home range core (i.e. the centroid) when they are with

141 more than one male compared to when they are not, and that (2) females will use their

142 preferred habitat less when they are with more than one male compared to when they

143 are not. However, this does not preclude consortships from affecting male space use.

144 Nonetheless, given that males have larger home ranges and greater habitat use

145 diversity than females, even if males do alter their space use during consortships, we

146 expect the relative impact of consortships on spatial ecology to be greater for females

147 than for males. Thus, we predict that (3) if males do experience space use shifts during

148 consortships, such shifts in both ranging and habitat use will be relatively greater for

149 females than for males when the sexes are together. Female-biased space use shifts

150 would suggest that females suffer an ecological cost in this coercive mating system.

153 METHODS

155 Study Population and Site

156 Our study population consists of individually recognised wild Indian Ocean

157 bottlenose dolphins (Tursiops cf. aduncus) residential to Shark Bay, Western Australia

158 (Mann et al. 2000; Tsai and Mann 2013). As part of the Shark Bay Dolphin Research

159 Project (SBDRP), researchers have collected behavioural, demographic, reproductive,

160 ecological, social, and genetic data on $>1800$ dolphins since 1984. Individuals are

161 distinguished using standard dorsal fin identification techniques (Würsig and Würsig 
162 1977). Sex is determined by the presence of a dependent calf, views of the genital area

163 (Smolker et al. 1992), and in a few cases, DNA (Krützen et al. 2004). Age is determined

164 from known or estimated birthdates (if seen as a calf), physical and behavioural

165 characteristics (Mann and Smuts 1999), and/or the presence and degree of ventral

166 speckling (Krzyszczyk and Mann 2012).

167 Our main study site is a $300 \mathrm{~km}^{2}$ area of the eastern gulf of Shark Bay $\left(25^{\circ} 47^{\prime} \mathrm{S}\right.$,

$168113^{\circ} 43^{\prime}$ E) within a UNESCO World Heritage Site, and as a result, remains relatively

169 pristine with low human impact. Habitat in the study area, as defined by Patterson

170 (2012), consists of six distinct types (average depths reported relative to datum):

171 channel (7.13 $\mathrm{m})$ with a substrate of rock, shell, and coral debris, deep open (6.56 m)

172 with a mixed sand, silt and clay substrate, seagrass beds $(2.00 \mathrm{~m})$ with continuous

173 seagrass coverage (predominantly Amphibolis antarctica and more sparsely Posidonia

174 australis), sand flats $(-0.11 \mathrm{~m})$ with continuous sand coverage, and two edge habitats:

175 deep ecotone, the transition zone between a shallow (seagrass beds or sand flats) and

176 deep (channel or deep open) habitat and shallow ecotone, the transition zone between

177 two shallow habitats (seagrass beds and sand flats). Relative habitat availability was

178 calculated as the proportion of the study area with coverage of that habitat type

179 (Patterson 2012).

180

181

182 Data Collection

183

184 Survey records 
185 Data collection for the SBDRP consists primarily of observational, boat-based

186 records. For this study data were drawn from surveys, which are opportunistic sightings

187 of dolphins, conducted from 1988-2012. A survey began when observers are close

188 enough to identify or photograph individuals. Scan sampling (Altmann 1974; Mann

189 1999) is used for the first five minutes of a survey to determine group composition and

190 activity. Group membership was determined using a 10-meter chain rule, where all

191 individuals within 10 meters of another group member were considered to be in

192 association (Smolker et al. 1992). Predominant group activity was recorded as the

193 behaviour that $\geq 50 \%$ of the group members engaged in during the scan in the first five

194 minutes. Spatial data (latitude and longitude) were also collected during each survey, to

195 later be used in classifying each survey's habitat based on the aforementioned habitat

196 classifications. If an individual had more than one survey sighting in a day, we restricted

197 our dataset to include only the last survey point per individual per day to reduce spatial

198 and temporal correlation.

200 Female cycling

$201 \quad$ Male interest in females is expected to vary with female reproductive status.

202 Thus, we included female cycling status (whether or not she was cycling) as the first

203 factor in our study. Bottlenose dolphins are seasonally polyoestrous with an estimated

204 6-month peak cycling period prior to the 12-month pregnancy (Schroeder 1990;

205 O'Brien and Robeck 2012). Accordingly, we assigned cycling periods as the 6-month

206 period before the start of known pregnancies (from known births). However, this

207 definition biases observations against females who have produced no or few surviving 
208 calves, or have long intervals between nursing calves since they are potentially fertile 209 during periods when no pregnancies are confirmed by a birth. Consequently, we

210 included additional time periods in which a female could be cycling, based on the

211 period: a) from the female's $12^{\text {th }}$ birthday (when $42.4 \%$ of first births occur, while $22.0 \%$

212 occur at age $11, N=59$ adult females where age of first birth was known) until her first

213 known pregnancy, and b) one year prior to weaning date for calves that nursed beyond

214 the age of four, the average weaning age (average interbirth interval between surviving

215 calves is 4.7 years; Mann et al. 2000). This method overestimates cycling periods

216 (increasing the risk of Type II error), but since females go through several non-

217 conceptive cycles per year, it conservatively accounts for potential fertile periods. Since

218 most of our data (76\% of surveys) were collected during the 6 months prior to the

219 November peak births/conceptions (Mann et al. 2000), we have adequate coverage

220 over periods of cycling. Females were considered to be non-cycling if they were (1)

221 pregnant, or (2) nursing a calf that was at least 12 months from its weaning date. Thus,

222 our cycling factor has two levels: cycling and not cycling. Females under age 12 were

223 excluded from analysis.

224

225 Male presence

$226 \quad$ Individual pairs or trios of males (first-order alliances) typically have very strong

227 bonds, with half-weight coefficients of association (COAs) as high as 0.8-1.0 (Connor et

228 al. 1992a, b; 2011). Second-order alliances are composed of two or more first-order

229 alliances (Connor and Vollmer 2009) with COAs ranging from 0.24-0.67 (Connor \&

230 Krützen 2015), and third-order alliances are composed of second-order alliances and 
231 their close male associates with slightly lower COAs ranging from $0.10-0.17$ (Connor et

232 al. 2011). Because males are found so frequently with their alliance partners and very

233 rarely with non-partners, as a proxy for consortships we used the presence of more than

234 one adult male in a survey. Males were considered to be adult at 12 years of age or

235 older (Cheal and Gales 1992). Thus, we used male presence as the second factor in

236 our study, having two levels: $>1$ male present, in which more than one adult male was

237 present in the survey (representing the minimal unit for allied coercion), and males

238 absent, in which no adult males were present in the survey. Here, single-male

239 associations were omitted. Males and females are monomorphic and there is no

240 evidence that a single male can monopolise a female. Although allied aggression

241 towards females is frequently observed (Connor et al. 1996; Scott et al. 2005),

242 aggression by a lone adult male towards an adult female has never been observed in

24328 years of study and 3467 hours of focal observation on 127 adult females (Scott et al.

244 2005; unpublished data). Further, associations between single males and single or

245 multiple females are rare (Table I). Nevertheless, for a subset of females in our sample,

246 we included a third level for the male factor: surveys in which a single male was present

247 with at least one adult female (see Supplementary Material).

248

249 Data Analysis

250

251 Cycling status (cycling or not cycling) and adult male presence (males absent,

252 one male present, $>1$ male present) were included as factors in our analyses. Since

253 reproductively successful females spend most of their adult life pregnant and/or 
254 lactating, not cycling, and rarely in association with males (Gibson and Mann 2008), we 255 considered the baseline state to be surveys when females were not cycling and males

256 were absent. We conducted a similar analysis on males to examine if their behaviour is

257 impacted by the presence of a female. Males spend most of their time with each other

258 (Connor et al. 1992a, b; 2011) and not in consortships, so we considered the male

259 baseline state to be surveys when no adult females were present (females absent) and

260 there was at least one additional adult male present. The male baseline was compared

261 to surveys where males were with at least one female (cycling or non-cycling), resulting

262 in a single factor with three levels for the male analysis (no females, only non-cycling

263 female(s) present, and only cycling female(s) present). Dolphins were included in the

264 sample if they had a minimum of six survey sightings on different days in each factor

265 level (e.g. cycling female with males; one point possible for each habitat based on

266 habitat availability), and the same females $(N=32)$ and males $(N=73)$ were used for all

267 analyses (the smaller sample size for females reflects the additional cycling restriction).

268 A subset of 11 females with adequate survey data was analysed using the single-male

269 comparison (results shown in the Supplementary Material). For all analyses regardless

270 of overall significance tests, we conducted a priori contrasts between all three levels of

271 male presence.

272

273 Ranging

274 As a measure of core ranging we calculated a baseline centroid for each

275 individual by averaging all GPS locations from survey records in the baseline state.

276 Centroids for males and females were calculated for their baseline state excluding 
277 sightings from all other factor levels. To examine if ranging differed with cycling status 278 and male presence (for females) or with female presence including cycling status (for 279 males), we compared the distances between the baseline centroid and each survey 280 GPS record within each factor level using permutation tests with dolphin ID as a 281 blocking factor. While somewhat counterintuitive, we also compared the distance of the 282 baseline centroid to each baseline survey point used in its calculation, as this serves as 283 the best measure of expected distance from the baseline centroid if there were no effect 284 of male presence or cycling status. We then compared the distances from the baseline 285 for each sex when they were found together to determine if females and males 286 differentially shifted in ranging. The average number of surveys $( \pm S D)$ per female, per 287 factor level was $102.75 \pm 103.24$ (not cycling, males absent), $21.13 \pm 14.50$ (not cycling, $288>1$ male present), $46.31 \pm 38.96$ (cycling, males absent), and $26.41 \pm 17.32$ (cycling, $>1$ 289 male present). The average number of surveys $( \pm S D)$ per male, per factor level was $29043.69 \pm 17.57$ (females absent), $66.97 \pm 53.15$ (cycling female(s) present) and $15.38 \pm$ 2918.70 (only non-cycling female(s) present).

292 To further understand how cycling and male presence influence female ranging, 293 and how female presence influences male ranging, we also calculated the average 294 pairwise distance between all sightings for each individual within each factor level 295 (hereafter average ranging distance). We examined the effect of cycling, male 296 presence, and their interaction (for females), and the effect of female presence (for 297 males) on this average ranging distance using permutation tests.

299 Habitat use 
After spatially intersecting our survey sightings with the six habitat classifications,

301 we quantified individual preferred (hereafter primary) habitat use using selection ratios.

302 Selection ratios indicate habitat selection by an individual while correcting for habitat

303 availability. Selection ratios were calculated as the proportional use of a habitat divided

304 by the proportional availability of that habitat (Manly et al. 2002). Values greater than

305 one indicate selection above expected based on availability, values less than one

306 indicate selection below expected based on availability, and values equal to one

307 indicate selection in accordance with availability. We ranked each individual's baseline

308 habitats $\left(1^{\circ}, 2^{\circ}, 3^{\circ}\right.$, etc. $)$ in descending order by their selection ratio, with the primary

$309\left(1^{\circ}\right)$ habitat having the highest value. Habitat use shifts were examined as a function of

310 cycling status and male presence (for females) and female presence including cycling

311 status (for males), using distanced-based, permutation MANOVAs with dolphin ID as a

312 blocking factor. In this analysis the last-ranked habitat $\left(6^{\circ}\right)$ was dropped since otherwise

313 the response would be linearly dependent.

314 Because many dolphins, mostly females, specialise in habitat-specific foraging

315 tactics (Sargeant et al. 2007, 2005; Mann et al. 2008; Patterson and Mann 2011), we

316 examined primary habitat use alone with permutation independence tests. We expected

317 the primary habitat to be the most important habitat for females and likely the most

318 affected by male presence. We then compared the primary habitat use selection ratio

319 for each sex when they were found together to determine if females and males

320 differentially changed use of their primary habitat. The average number of surveys $( \pm$

321 SD) per female, per factor level was $99.94 \pm 103.97$ (not cycling, males absent), $20.13 \pm$

32214.00 (not cycling, >1 male present), $44.38 \pm 38.42$ (cycling, males absent), and $23.78 \pm$ 
32315.05 (cycling, $>1$ male present). The average number of surveys ( \pm SD) per male, per

324 factor level was $36.89 \pm 17.24$ (females absent), $57.16 \pm 49.43$ (cycling female(s)

325 present), and $14.35 \pm 8.25$ (only non-cycling female(s) present). See the Interactive

326 Map for a visualization of habitats in the study area as well as representative male and 327 female spatial data by factor level.

328

329 Statistical considerations

330 All of our response variables deviated significantly from normality (all Shapiro-

331 Wilk tests $P<0.01$ ), thus permutation tests were used in all analyses (Anderson 2001).

332 Permutations (1000 randomizations) were performed using the coin package (Hothorn

333 et al. 2006) in R, version 3.2.1 (R Core Team 2015), except for the female habitat and

334 ranging distance analyses in which custom permutations tests were written using the

335 Ime4 package for $\mathrm{R}$ (Bates 2014) to test for interaction (Anderson 2001). Permutation

336 MANOVAs were performed using the adonis() function in the vegan package for $\mathrm{R}$

337 (Oksanen et al. 2013), which permutes the raw data and calculates a pseudo- $\mathrm{F}$ using a

338 multivariate distance measure, here the Bray-Curtis distance. For all analyses, the

339 interactions were tested and tests for main effects were only performed if interactions

340 were determined to be non-significant. Significance was set at $\alpha=0.05$ for all tests, and

341 Bonferroni adjustments were applied where there were multiple contrasts and the

342 corrected $P$-values are reported. Female centroid distances were natural-log

343 transformed to correct for heteroscedasticity (Levene's test $P<0.01$ ), but raw distance

344 values are reported for illustrative purposes. 


\section{RESULTS}

\section{Female associations with males}

350 Table I shows that adult females spend most of their time either alone or with

351 other adult females. Females are with $>1$ male about one-third of the time when cycling,

352 and are very rarely with lone males regardless of reproductive state. These descriptive 353 data provide context for our results.

$354 \quad$ For all the following analyses, results from the single-male associations were

355 either not significant or largely intermediate between male-absent and multi-male

356 associations (see Figure S1a-c, Table S1). As evident from Table I, the instances of

357 single-male association with females are rare and our sample sizes were limited. See

358 the Supplementary Material for all single male results and discussion.

359

360

$361 \quad$ Ranging

There was no interactive effect of cycling status and male presence on distance

363 from baseline for females $(F=0.24, P=0.63)$, so main effects are reported. Both

364 cycling status $(Z=-4.30, P<0.0001)$ and male presence $(Z=-7.08, P<0.0001)$

365 influenced the distance (natural log-transformed) a female was found from her baseline

366 centroid. Females were sighted farthest from their baseline centroid when they were

367 with males, and also when they were cycling (Fig. 1a). In contrast, male distances from

368 their baseline centroid were unrelated to female presence or female cycling status 
$369(\max T=1.63, P=0.20$; Fig. 2a). In comparing male and female distances from their

370 baselines to when there was at least one female and $>1$ adult male in the group, the

371 distances of each sex to their respective baseline centroids differed $(Z=-2.35, P=$

372 0.02), with males being farther from their baseline centroid than females.

373 Females' average ranging distance was not influenced by an interaction between

374 cycling status and male presence $(F=0.13, P=0.72)$ so main effects are reported.

375 Both cycling status $(Z=-2.55, P=0.009)$ and male presence $(Z=-3.06, P=0.003)$

376 affected a female's average ranging distance (Fig. 1b). Females had the highest

377 average ranging distance when cycling and $>1$ male was present, which was

378 significantly higher than the baseline state only $(Z=-3.56, P<0.0001)$ after a

379 Bonferroni correction (Fig. 1b). However, cycling females without males also had a 380 higher average ranging distance than females in the baseline state $(Z=-2.85, P=$ $381 \quad 0.001$; Fig. 1b).

$382 \quad$ Males' overall average ranging distance was influenced by female presence

$383(\max T=5.09, P<0.0001)$. Males had the highest average ranging distance when no

384 females were present compared to when non-cycling female(s) $(Z=4.79, P<0.0001)$

385 and cycling females $(Z=-2.77, P=0.005)$ were present (Fig. 2b). Average male

386 ranging distance was greater when cycling females were present compared to only non-

387 cycling female presence $(Z=3.24, P=0.002$; Fig. 2b).

388

389

390 Table I: Proportion of sightings per individual per factor level used in the full data set

391 (32 females; $N=4611$ surveys and 7004 female sightings). For analysis, surveys with 
392 one female and one male were lumped with those that had more than one female and 393 one male to form the one-male factor level.

394

\section{SIGHTING PROPORTION}

\begin{tabular}{|c|c|c|}
\hline & Not cycling & Cycling \\
\hline 9 or 9 ? & 0.715 & 0.551 \\
\hline 0.1 & 0.021 & 0.015 \\
\hline $0 \pi \lambda$ & 0.040 & 0.114 \\
\hline 00.1 & 0.073 & 0.071 \\
\hline $90, \hat{0}$ & 0.152 & 0.248 \\
\hline
\end{tabular}

395

$396 \hat{\jmath}=1$ adult male present, $\hat{\sigma} \hat{\sigma}=>1$ adult male present.

$397 \rightarrow=1$ adult female present, $q \uparrow=>1$ adult female present.

400 Figure 1: Adult female $(N=32)$ (a) distance from the baseline centroid, (b) average 401 ranging distance, and (c) primary habitat selection ratios for each combination of cycling 402 and male presence factor levels. Error bars indicate \pm 1 SE. Letters indicate significant 403 differences after Bonferroni adjustments. Distances in (a) were natural log-transformed 404 for analysis but raw distances are shown for illustrative purposes.

406 (see source file)

407

408 Figure 2: Adult male $(N=73)$ (a) distance from the baseline centroid, (b) average 409 ranging distance, and (c) primary habitat selection ratios for each factor level. Error bars 410 indicate \pm 1 SE. For distance from baseline centroid, no significant differences across 
411 groups. For average ranging distance and habitat selection ratios (b), letters indicate

412 significant differences after Bonferroni adjustments.

414 (see source file)

417 Habitat use

418 The interaction between male presence and cycling status on overall female

419 habitat use was not significant (Table II). However, overall female habitat use did

420 change significantly as a function of male presence, but not cycling status (Table II). Per

421 our a prioriprediction, we examined the effect of cycling and male presence on female

422 primary habitat alone (Fig. 1c). There was no interaction between cycling status and

423 male presence on primary habitat use $(F=0.44, P=0.53)$ so only main effects are

424 reported. Consistent with the results from the MANOVA, all females used their primary

425 habitat less when in the presence of $>1$ male $(Z=3.32, P=0.0003)$, independent of

426 cycling status, which itself was not significant $(Z=0.28, P=0.78)$. In the baseline state,

427 females were sighted in their primary habitat $62 \%$ of the time, and this decreased by an

428 average of $15 \%$ when $>1$ male was present.

429 Overall male habitat use changed as a function of female presence (Table II), as

430 did the primary habitat when analysed alone $(\max T=3.54, P=0.001)$. Males used their

431 primary habitat less when either cycling or non-cycling females were present compared

432 to when no females were present (cycling females: $Z=-4.25, P<0.0001$; non-cycling

433 females: $Z=2.59, P=0.008$; Fig. 2c). However, male habitat use did not differ 
434 depending on if they were with cycling females or non-cycling females $(Z=0.23, P=$

435 0.84). In baseline, males were sighted in their primary habitat $54 \%$ of the time, and this

436 decreased by an average of $4 \%$ when either cycling or non-cycling females were

437 present. In comparing the reduction in primary habitat use between males and females

438 from their baseline to when there was at least one female and $>1$ adult male in the

439 group, the reduction in primary habitat use did not differ between the sexes $(Z=0.54, P$

$440=0.58)$.

443 Table II: MANOVA results for overall female habitat use selection ratios and the effect

444 of female cycling status and male presence, and overall male habitat use selection

445 ratios and the effect of female presence including cycling status. $\mathrm{df}=$ degrees of

446 freedom, $M S=$ mean squares, $F=$ model statistic from the permuted $F$-tests, $R^{2}=$

447 adjusted $\mathrm{R}$-squared or effect size, $\mathrm{P}=$ significance value.

448

\begin{tabular}{llrrrrr}
\hline & df & MS & $\mathbf{F}$ & $\mathbf{R}^{2}$ & $\mathbf{P}$ \\
\hline Females & Cycling & 1 & 0.05 & 0.66 & 0.01 & 0.29 \\
& Male presence & 1 & 0.19 & 2.33 & 0.02 & $<0.01$ \\
& Cycling*Male presence & 1 & 0.04 & 0.55 & 0.00 & 0.37 \\
& Residual & 124 & 9.85 & & 0.97 & \\
\hline Males & Female presence & 2 & 0.12 & 1.40 & 0.01 & 0.03 \\
& Residual & 216 & 0.09 & & 0.99 & \\
\hline
\end{tabular}


$454 \quad$ Our findings are consistent with the sexual coercion hypothesis that allied males

455 impose ecological costs on females, in that females experienced space use shifts when

456 in the presence of more than one adult male. Specifically, females were sighted farthest

457 from their baseline centroid, had greater average ranging distances, and showed

458 altered habitat use when with more than one male, regardless of cycling status.

459 Interestingly, cycling status alone also affected female ranging in that females had

460 greater ranging distances and were found farther from their baseline when cycling,

461 regardless of male presence. This suggests an overall change in ranging, although not

462 habitat use, during cycling that may be unrelated to mating. Together, our results

463 suggest that allied male coercion imposes ecological costs on female bottlenose

464 dolphins, but some range shifts may occur outside of consortships when females are 465 cycling.

$466 \quad$ Males did not experience as great a shift in their spatial ecology during mating

467 contexts as did females. Males were found equally far from their baseline whether or not

468 a female (either cycling or non-cycling) was present. However, male average ranging

469 distance decreased when with cycling and non-cycling females. This is unsurprising as

470 males are expected to range widely when searching for females, and preliminary data

471 suggest males have smaller home ranges during peak breeding in the spring (Randić

472 2008). When a female was present, male average ranging distance was higher if the

473 female was cycling, which suggests males a) match movement of the females they are

474 consorting, and/or b) maintain greater ranging to avoid detection or conflict with other

475 alliances. Both predictions corroborate our finding that female average ranging distance

476 was higher when cycling. While males did alter their overall habitat use and decreased 
477 their primary habitat use in the presence of females, this did not depend on a female's

478 cycling status. The lack of a cycling status effect here may indicate that males have

479 imperfect detection of female reproductive states. Females nurse calves for 2.5 to 9

480 years and often wean their calf during the next pregnancy (Mann et al. 2000;

481 unpublished data). With such long and variable lactation periods, male ability to detect

482 or predict female fertility is likely imperfect. Males have also been observed to consort

483 non-cycling and pregnant females (Connor et al. 1996, Furuichi et al. 2014), which may

484 be a male bonding tactic rather than about increasing the likelihood of conceptions per 485 se.

486

When directly comparing centroid and habitat shifts during sightings of possible

487 mating contexts (i.e. $>1$ male and $\geq 1$ female together in surveys), we found that males 488 experienced larger ranging shifts than females, and there was no habitat shift sex

489 difference. However, while the presence of males altered females' normal ranging 490 patterns (Fig. 1a), the same was not true for males when in the presence of females

491 (Fig. 2a); male centroid distance remained constant regardless of female presence 492 (cycling or non-cycling). Males typically have larger home ranges than females (Owen 493 et al. 2002; Urian et al. 2009; Patterson 2012; Randić et al. 2012; Sprogis et al. 2016;

494 but see Tsai and Mann 2013), so any shift they experience likely has less of an impact 495 on their overall space use compared to a similar shift in females. In fact, increased 496 ranging may actually be beneficial for males since the size of their home ranges is 497 associated with their coercive mating tactics (Randić et al. 2012), and alliances tend to 498 range more widely to maximise their search area and access to females (Randić 2012). 499 Further, while both males and females experienced similar primary habitat use shifts in 
500 mating contexts, adult males have higher habitat use diversity than adult females

501 (Patterson 2012), and don't specialise in foraging tactics nearly as much as females

502 (e.g. Mann and Sargeant 2003; Sargeant et al. 2005; Mann et al. 2008; 2012), so a shift

503 in primary habitat likely has less of an impact on male foraging than it would for more

504 specialised females.

$505 \quad$ While males experienced smaller shifts in their spatial ecology when with

506 females, our results clearly demonstrate ranging shifts for females in consortship

507 contexts that likely impose ecological costs. For example, adult female home ranges in

508 Shark Bay average $51 \mathrm{~km}^{2}$ (Tsai and Mann 2013), compared to $76 \mathrm{~km}^{2}$ for adult males

509 (Randić et al. 2012). Thus, the average centroid shift of $3 \mathrm{~km}$ when cycling and with

510 males reported here would likely place a female near the edge or outside of her home

511 range, if, as a conservative example, a female has a circular home range with an area

512 of $51 \mathrm{~km}^{2}$ and a radius of $4 \mathrm{~km}$.

513 Interestingly, female sightings were farther apart (ranging distance) and farther

514 from their baseline centroid when they were cycling regardless of male presence. Thus,

515 in general, cycling females appear to increase their ranging. For some of these females

516 that still have dependent calves, additional ranging may be especially costly, which

517 raises the question of why cycling females might increase their ranging behaviour. We

518 propose three possible explanations for increased movement during cycling, all of which

519 warrant further investigation. First, cycling females might increase ranging to avoid

520 detection by allied males. Second, females might increase ranging to avoid

521 consortships with specific alliances (e.g. reduce probability of incestuous matings, see

522 Frère et al. 2010a) and/or increase the chance of encountering preferred alliances or 
523 multiple male partners. Third, as an artifact of our study methods, females might be

524 sighted between consortships after males have already moved them far from their core

525 ranging area. Increased traveling during cycling has been reported in other systems: in

526 Mahale chimpanzees (Pan troglodytes schweinfurthii), estrous females travelled greater

527 distances (Hasegawa 1990) and spent more time moving than their anestrous

528 counterparts (Matsumoto-Oda and Oda 1998). In giraffes (Giraffa camelopardalis),

529 cycling females tended to locomote more than pregnant females (del Castillo et al.

530 2005). Lactating Grevy's zebra have elevated speeds compared to non-lactating

531 females, and these females experience the most male harassment (Sundaresan et al.

532 2007). In black-faced impalas (Aepyceros melampus petersi), post-parturient females

533 foraged in different microhabitats and elevations than pre-parturient females (Matson et

534 al. 2007), suggesting finer scale habitat decisions may indeed be influenced by

535 reproductive status alone. In contrast, in our study female cycling status influenced

536 average ranging distance and distance from baseline centroid, but not habitat use. This

537 suggests that although females do increase ranging and possibly their home range,

538 they appear to do so in way that maintains their preferred habitat use. Such range shifts

539 are not likely as costly as those experienced in a consortship context.

$540 \quad$ Females experienced overall habitat use shifts, and importantly a reduction in

541 primary habitat use, when with more than one male. Reduced primary habitat use has

542 direct implications for female foraging behaviour since many females specialise in

543 habitat-specific foraging tactics (Sargeant et al. 2007, 2005; Mann et al. 2008; Patterson

544 and Mann 2011). For instance, given that spongers are almost never sighted greater

545 than $6 \mathrm{~km}$ from their channel habitat (Mann and Patterson 2013), consorting by males 
546 almost certainly takes them in to unfamiliar habitat outside of their baseline area. In fact,

547 one sponger female in this study reduced her channel habitat use by $36 \%$ when she

548 was with males. In such a scenario, habitat and site unfamiliarity may present significant

549 challenges, such as extra search effort to find sponge tools and/or prey, which may alter

550 foraging success (Patterson et al. 2015). Indeed, previous work found that females

551 foraged less during consortships (Watson-Capps 2005), which could be because they

552 were spending less time in their primary foraging habitat. An examination of group

553 behaviour data from the surveys used in this study indicates that females have reduced

554 foraging budget in consortship contexts. Foraging was the predominant activity of

555 groups consisting of a female and more than one male only $20 \%$ of the time, compared

556 to $32 \%$ for groups of females without males. While such a reduction suggests an energy

557 intake cost to females as a result of male coercion, we emphasise that these group

558 behaviour data are not ideal for examining individual female changes in activity budgets

559 (Karniski et al. 2014). Instead, individual focal follow data should provide a more

560 accurate picture of female activity budgets with respect to cycling status and male

561 presence, a topic of our future work.

562 Together, our results suggest that males spatially sequester females during

563 consortships, from which they may gain several benefits. By sequestering females,

564 males likely impact the ability of females to counter their efforts. For example, on a

565 number of occasions, we have witnessed adult females appearing to "assist" other

566 females in consortships (see also Connor et al. 2006). In these cases, the assisting

567 female may join a group where males are harassing a close associate, and remain in

568 close proximity or even establish physical contact with her. While males may try to 
569 separate these females, the females sometimes succeed in leaving the group. By

570 spatially moving females away from their close associates, males might reduce the risk

571 that they will receive aid. Indeed, female social relationships are closely tied to their

572 home ranges (Frère et al. 2010b; Mann et al. 2012), so females displaced from their

573 preferred areas may not have their common female associates available, albeit

574 temporarily.

575 Another benefit of sequestration is that males may be able to reduce competition

576 from other alliances. Alliances vary in size (Connor et al. 1999; Randić et al. 2012) and

577 can be fiercely competitive, with larger alliances often defeating smaller ones (Connor et

578 al. 1999). Presumably this is why males cooperate in the first place - to increase their

579 ability to maintain exclusive access to a female even though they must share in matings

580 with alliance members. The best tactic for males might be to remove a female from an

581 area where other males are likely to search. Finally, by using coercion within or outside

582 of female cycling periods, males may be acting to increase their own reproductive

583 success, as has been found in chimpanzees (Feldblum et al. 2014).

$584 \quad$ While our data indicate that male coercion negatively impacts female spatial

585 ecology, three alternative, but non-mutually exclusive, explanations are possible. First,

586 females might actually alter their space use when cycling, and males simply follow them

587 in order to gain mating access. As noted above, females of a variety of mammalian

588 species increase their ranging during cycling for many reasons. However, we failed to

589 find an overall effect of cycling on habitat use. Thus for this alternative hypothesis to

590 hold, females would need to specifically alter their preferred habitat use only in the

591 company of males, or, males would need to only follow a female if she is both cycling 
592 and in a non-preferred habitat. While this is certainly possible, we are unaware of any

593 data that support this somewhat unusual scenario. Second, females might shift their

594 space use to avoid males, and thus the ecological shifts represent the costs of a female

595 counterstrategy to male aggression, rather than the cost of coercion itself. While we

596 cannot rule out this possibility, in such a scenario the threat of male coercion would still

597 impose an indirect cost on females if avoidance requires moving away from preferred

598 areas. Finally, rather than experiencing direct costs from sexual coercion, females may

599 be experiencing indirect costs as a result of a male strategy to reduce intrasexual

600 competition via spatial segregation. Since these two explanations result in the same

601 behaviour (females mating with sequestering males, and not other competing males),

602 we are unable to disentangle the root source of these ecological costs. If alliance

603 formation and maintenance is actually a strategy to reduce male competition,

604 particularly in areas where males have a high encounter rate (Connor and Whitehead

605 2005; Connor and Krützen, 2015) and encounters with cycling females are rare, then

606 coalitionary aggression, sequestration, and monopolization of individual females may be

607 the best way for males to achieve mating success. Future studies employing focal follow

608 methods on individual females with and without males, in all reproductive states, may

609 prove useful in ruling out these alternative explanations.

610 Currently, the costs of sexual conflict are not well understood, especially among

611 long-lived mammals where fitness outcomes can take decades to assess (Aloise King

612 et al. 2013), and female counterstrategies may be in place (Palombit 2014). However,

613 our results suggest that in bottlenose dolphins, males have a significant impact on

614 female space use that likely impacts foraging behaviour and potentially fitness. Given 
615 that female bottlenose dolphins spend weeks or even months in consortships (Connor

616 et al. 1996), these spatial, ecological costs may be long lasting. For reproductively

617 successful females that nurse calves for three or more years and cycle about every 4-5

618 years, consortship frequency, and thus the costs of male coercion may be low.

619 However, for females with low calving success, repeated annual consortship events

620 might have more severe negative impacts. As such, the fitness costs of sexual conflict

621 to females in the bottlenose dolphin mating system deserve further study.

622 Our study contributes to the growing body of literature documenting behavioural

623 costs to coercive mating, and provides clear evidence for the costs of allied male

624 aggression in a non-human species. In other coercive systems, the threat of male

625 coercion forces female avoidance (e.g. guppies Poecilia reticulata, Darden and Croft

626 2008), and even sexual social segregation (e.g. small-spotted catsharks Scyliorhinus

627 canicula, Wearmouth et al. 2012). Male chimpanzees lead females away in

628 consortships, effectively mate guarding (Tutin 1979). However, all known cases involve

629 single male harassment of females (but see Watts 1998), and we are unaware of any

630 cases where males engage in stable and long-term cooperation to coerce females as in

631 bottlenose dolphins. Importantly, few studies have looked at the relationship between

632 coercion, female reproductive status, and the effects on individual ecology. Such an

633 integrative approach is important for understanding the mechanisms by which coercion

634 can influence female fitness, and ultimately the evolution of mating systems.

635

636

637 


\section{ACKNOWLEDGEMENTS}

639

640 We thank current and past members of the SBDRP, and numerous field assistants, for

641 their efforts in data collection used for this project, as well as two anonymous reviewers

642 for helpful comments on an earlier draft of this manuscript. We also thank the Western

643 Australia Department of Parks and Wildlife (DPaW) and the Monkey Mia Dolphin Resort

644 for their logistical support in the field. This work was approved by the Georgetown

645 University Animal Care and Use Committee, permit \#07-041, \#10-023, \#13-

646 069, DPaW permit \#SF007418, \#SF007975, \#SF006897, \#SF007457, \#SF009311,

647 \#SF008076, \#SF009876, and The University of Western Australia animal ethics permit

648 \#600-37. The study was funded by NSF grants 0941487, 0918308, 0316800, National

649 Geographic Society Committee for Research and Exploration, ONR BAA 10230702, 650 and Georgetown University.

651

652

653 LITERATURE CITED

654

655 Aloise King, E. D., Banks, P. B., and Brooks, R. C. (2013). Sexual conflict in mammals:

656 consequences for mating systems and life history. Mammal Review, 43, 47-58.

657 Altmann, J. (1974). Observational study of behavior: sampling methods. Behaviour, 49, $658 \quad 227-266$. 
659 Anderson, M. J. (2001). Permutation tests for univariate or multivariate analysis of 660 variance and regression. Canadian Journal of Fisheries and Aquatic Sciences, $661 \quad 58,626-639$.

662 Bates, D., Maechler, M., Bolker, B., and Walker, S. (2014). Ime4: Linear mixed-effects 663 models using Eigen and S4. R package version 1.1-7. http://cran.r-

664 project.org/package=Ime4.

665 Cartwright, R. and Sullivan, M. (2009). Associations with multiple male groups increase 666 the energy expenditure of humpback whale (Megaptera novaeangliae) female 667 and calf pairs on the breeding grounds. Behaviour, 146, 1573-1600.

668 del Castillo, S. M., Bashaw, M. J., Patton, M. L., Rieches, R. R., and Bercovitch, F. B.

669 (2005). Fecal steroid analysis of female giraffe (Giraffa camelopardalis)

670 reproductive condition and the impact of endocrine status on daily time budgets.

$671 \quad$ General and Comparative Endocrinology, 141, 271-281.

672 Cheal, A.J. and Gales, N.J. (1992). Growth, sexual maturity and food-intake of

673 Australian Indian Ocean bottlenose dolphins, Tursiops-truncatus, in

674 captivity. Australian Journal of Zoology, 40, 215-223.

675 Clutton-Brock, T. H. and Parker, G. A. (1995). Sexual coercion in animal societies.

$676 \quad$ Animal Behaviour, 49, 1345-1365.

677 Connor, R. C., Smolker, R. A., and Richards, A. F. (1992a). Two levels of alliance 678 formation among male bottlenose dolphins (Tursiops sp.). Proceedings of the 679 National Academy of Sciences of the United States of America, 89, 987-90. 680 Connor, R. C., Smolker, R. A., and Richards, A. F. (1992b). Dolphin Alliances and 681 Coalitions. In A. H. Harcourt and F. B. M de Waal (Eds.) Coalitions and Alliances 

University Press.

684 Connor, R. C., Richards, A., Smolker, R., and Mann, J. (1996). Patterns of female 685 attractiveness in Indian Ocean bottlenose dolphins. Behaviour, 133, 37-69.

686 Connor, R. C. and Smolker, R. (1996). "Pop" goes the dolphin: a vocalization male 687 bottlenose dolphins produce during consortships. Behaviour, 133, 643-662.

688 Connor, R. C., Heithaus, M. R., Barre, L. M., Spoor, F., Higgins, P. O., Dean, C., and 689 Lieberman, D. E. (1999). Superalliance of bottlenose dolphins. Nature, 397, 571$690 \quad 572$.

691 Connor, R. C., Heithaus, M. R., and Barre, L. M. (2001). Complex social structure, 692 alliance stability and mating access in a bottlenose dolphin 'super-alliance'. Proc.

$693 \quad$ R. Soc. Lond. B, 268, 263-267.

694 Connor, R. C. and Whitehead, H. (2005). Alliances II: rates of encounter during 695 resource utilization: a general model of intrasexual alliance formation in fission696 fusion societies. Animal Behaviour, 69, 127-132.

697 Connor, R. C., Mann, J., and Watson-Capps, J. J. (2006). A sex-specific affiliative 698 contact behavior in Indian Ocean bottlenose dolphins, Tursiops sp. Ethology, $699 \quad 112,631-638$.

700 Connor, R. C. and Vollmer, N. L. (2009). Sexual coercion in dolphin consortships: a

701 comparison with chimpanzees. In M. N. Muller and R. W. Wrangham (Eds.), 702 Sexual Coercion in Primates and Humans (pp. 218-243), Cambridge, MA,

$703 \quad$ U.S.A.: Harvard University Press. 
704 Connor, R. C., Watson-Capps, J. J., Sherwin, W. S., and Krützen, M. (2011). A new

705 level of complexity in the male alliance networks of Indian Ocean bottlenose

706 dolphins (Tursiops sp.). Biology Letters, 7, 623-626.

707 Connor, R. C. and Krützen, M. (2015). Male dolphin alliances in Shark Bay: changing

708 perspectives in a 30-year study. Animal Behaviour, 103, 223-235.

709 Darden, S. K. and Croft, D. P. (2008). Male harassment drives females to alter habitat

710 use and leads to segregation of the sexes. Biology Letters, 4, 449-51.

711 Darden, S. K., James, R., Ramnarine, I. W., and Croft, D. P. (2009). Social implications

712 of the battle of the sexes: sexual harassment disrupts female sociality and social

713 recognition. Proceedings of the Royal Society B, 276, 2651-6.

714 Darden, S. K. and Watts, L. (2012). Male sexual harassment alters female social 715 behaviour towards other females. Biology Letters, 8, 186-188.

716 Feldblum, J. T., Wroblewski, E. E., Rudicell, R. S., Hahn, B. H., Paiva, T., Cetinkaya-

717 Rundel, M., Pusey, A., and Gilby, I. C. (2014). Sexually coercive male

718 chimpanzees sire more offspring. Current Biology, 24, 2855-2860.

719 Frère, C., Krützen M., Kopps, A., Ward, P., Mann, J., and Sherwin, W. B. (2010a).

720 Inbreeding tolerance and fitness costs in wild bottlenose dolphins. Proceedings

$721 \quad$ of the Royal Society B, 277, 2667-2673.

722 Frère, C. H., Krützen, M., Mann, J., Watson-Capps, J. J., Tsai, Y. J., Patterson, E. M.,

723 Connor, R.C., Bejder, L., and Sherwin, W. B. (2010b). Home range overlap,

724 matrilineal and biparental kinship drive female associations in bottlenose

725 dolphins. Animal Behaviour, 80, 481-486. 
726 Furuichi, T., Connor, R. C., and Hashimoto, C. (2014). Non-conceptive sexual

727

728

729

730

731

732

733

734

735

736

737

738

739

740

741

742

743 Heithaus, M.R. and Dill, L.M. (2006). Does tiger shark predation risk influence foraging

744

745

746 Heubel, K. U. and Plath, M. (2008). Influence of male harassment and female

747 interactions in monkeys, apes \& toothed whales. In J. Yamagiwa and L. Karczmarski (Eds.) Primates \& cetaceans: Field research and conservation of complex mammalian societies (pp. 385-408). Tokyo, Japan: Springer.

Galimberti, F., Boitani, L., and Marzetti, I., (2000). The frequency and costs of harassment in southern elephant seals. Ethology Ecology \& Evolution, 12, 345365.

Gay, L., Eady, P. E., Vasudev, R., Hosken, D. J., and Tregenza, T. (2009). Costly sexual harassment in a beetle. Physiological Entomology, 34, 86-92.

Gibson, Q. A. and Mann, J. (2008). The size, composition and function of wild bottlenose dolphin (Tursiops sp.) mother-calf groups in Shark Bay, Australia. Animal Behaviour, 76, 389-405.

Hasegawa, T. (1990). Sex differences in ranging patterns. In T. Nishida (Ed.) The Chimpanzees of the Mahale Mountains (pp. 99-114), Japan: University of Tokyo Press.

Heithaus, M. and Dill, L. (2002). Food availability and tiger shark predation risk influence bottlenose dolphin habitat use. Ecology, 83, 480-491. habitat use by bottlenose dolphins at multiple spatial scales? Oikos, 114, 257264.

competition on female feeding behaviour in a sexual-asexual mating complex of 
mollies (Poecilia mexicana, P. formosa). Behavioral Ecology and Sociobiology, 62, 1689-1699.

750 Hiruki, L. M., Stirling, I., Gilmartin, W. G., Johanos, T. C., and Becker, B. L. (1993). Significance of wounding to female reproductive success in Hawaiian monk seals (Monachus schauinslandi) at Laysan Island. Canadian Journal of Zoology, 71, 469-474.

754 den Hollander, M. and Gwynne, D. T. (2009). Female fitness consequences of male harassment and copulation in seed beetles, Callosobruchus maculatus. Animal

757 Hothorn, T., Hornik, K., van de Wiel, M. A., and Zeileis, A. (2006). A Lego system for 758

Karniski, C., Patterson, E. M., Krzyszczyk, E., Foroughirad, V., Stanton, M., and Mann, J. (2015). A comparison of survey and focal follow methods for estimating individual activity budgets of cetaceans. Marine Mammal Science.

763

764

765

766

767

768

769

770

DOI:10.1111/mms.12198

Köhler, A., Hildenbrand, P., Schleucher, E., Riesch, R., Arias-Rodriguez, L., Streit, B., and Plath, M. (2011). Effects of male sexual harassment on female time budgets, feeding behavior, and metabolic rates in a tropical livebearing fish (Poecilia mexicana). Behavioral Ecology and Sociobiology, 65, 1513-1523.

Krützen, M., Sherwin, W. B., Berggren, P., and Gales, N. (2004). Population structure in an inshore cetacean revealed by microsatellite and mtDNA analysis: bottlenose dolphins (Tursiops sp.) in Shark Bay, Western Australia. Marine Mammal Science, 20, 28-47. 
771 Krzyszczyk, E. and Mann, J. (2012). Why become speckled? Ontogeny and function of speckling in Shark Bay bottlenose dolphins (Tursiops sp.). Marine Mammal Science, 28, 295-307.

774 Link, A., De Fiore, A., and Spehar, S. N. (2009). Female-directed aggression and social 775 control in spider monkeys. In M. N. Muller and R. W. Wrangham (Eds.), Sexual

776 Coercion in Primates and Humans (pp. 157-183), Cambridge, MA, U.S.A.:

778 Le Boeuf, B. and Mesnick, S. (1991). Sexual behavior of male northern elephant seals:

779 I. Lethal injuries to adult females. Behaviour, 116, 143-162.

780 Manly, B. F. J., Mcdonald, L. L., Thomas, D. L., McDonald, T. L. and Erickson, W. P. 781 2002. Resource Selection by Animals Statistical Design and Analysis for Field 782 Second Edition. 2nd edn. Dordrecht: Kluwer Academic Press.

783 Mann, J. (1999). Behavioral sampling methods for cetaceans: a review and critique.

$784 \quad$ Marine Mammal Science, 15, 102-122.

785 Mann, J. and Smuts, B. (1999). Behavioral development in wild bottlenose dolphin 786 newborns (Tursiops sp). Behaviour, 136, 529-566.

787 Mann, J., Connor, R. C., Barre, L. M., and Heithaus, M. R. (2000). Female reproductive 788 789 success in bottlenose dolphins (Tursiops sp.): life history, habitat, provisioning, and group-size effects. Behavioral Ecology, 11, 210-219.

790 Mann, J., and Sargeant, B. (2003). Like mother, like calf: the ontogeny of foraging 791 traditions in wild Indian ocean bottlenose dolphins (Tursiops sp.). In D. M.

792 Fragaszy and S. Perry (Eds.), The Biology of Traditions (pp. 236-266),

$793 \quad$ Cambridge, MA, U.S.A.: Cambridge University Press. 
794 Mann, J., Sargeant, B. L., Watson-Capps, J. J., Gibson, Q. A., Heithaus, M. R., Connor, 795 R. C., and Patterson, E. (2008). Why do dolphins carry sponges? PloS ONE, 3, $796 \quad$ e3868.

797 Mann, J., Stanton, M. A., Patterson, E. M., Bienenstock, E. J., and Singh, L. O. (2012). 798 Social networks reveal cultural behaviour in tool-using dolphins. Nature $799 \quad$ Communications, 3, 980.

800 Mann, J. and Patterson, E. M. (2013). Tool use by aquatic animals. Philosophical $801 \quad$ Transactions of the Royal Society B, 368, 20120424.

802 Matson, T.K., Putland, D. A., Jarman, P. J., le Roux, J., and Goldizen, A. W. (2007). 803 Influences of parturition on home range and microhabitat use of female black804 faced impalas. Journal of Zoology, 271, 318-327.

805 Matsumoto-Oda, A., and Oda, R. (1998). Changes in the activity budget of cycling 806 female chimpanzees. American Journal of Primatology, 46, 157-166.

807 Muller, M. N., Kahlenberg, S. M., Thompson, M. E., and Wrangham, R. W. (2007). Male 808 coercion and the costs of promiscuous mating for female chimpanzees.

809 Proceedings of the Royal Society B, 274, 1009-1014.

810 Muller, M. N., Kahlenberg, S. M., and Wrangham, R. W. (2009). Male aggression 811 against females and sexual coercion in chimpanzees. In M. N. Muller and R. W. 812 Wrangham (Eds.), Sexual Coercion in Primates and Humans (pp. 184-217), 813 Cambridge, MA, U.S.A.: Harvard University Press.

814 Noë, R. (1992). Alliance formation among male baboons: shopping for profitable 815 partners. In A. H. Harcourt and F. B. M de Waal (Eds.) Coalitions and Alliances in 
$817 \quad$ University Press.

818 O'Brien, J. K. and Robeck, T. R. (2012). The relationship of maternal characteristics and

819 circulating progesterone concentrations with reproductive outcome in the

820 bottlenose dolphin (Tursiops truncatus) after artificial insemination, with and

821 without ovulation induction, and natural breeding. Theriogenology, 78, 469-482.

822 Ojanguren, A. F., and Magurran, A. E. (2007). Male harassment reduces short-term

823 female fitness in guppies. Behaviour, 144, 503-514.

824 Oksanen, J., Blanchet, F. G., Kindt, R., Legendre, P., O'Hara, R.B., Simpson, G. L., 825 Solymos, P., Stevens, M. H. H. and Wagner, H. (2013). vegan: Community

826 ecology package. R package version 2.0-10. http://CRAN.R-

827 project.org/package=vegan

828 Owen, E., Wells, R. S. and Hofmann, S. (2002). Ranging and association patterns of 829 paired and unpaired adult male Atlantic bottlenose dolphins, Tursiops truncatus, 830 in Sarasota, Florida, provide no evidence for alternative male strategies.

831 Canadian Journal of Zoology, 80, 2072-2089.

832 Palombit, R. A. (2014). Sexual conflict in nonhuman primates. Advances in the Study of 833 Behavior, 46, 191-280.

834 Panhuis, T. M., Butlin, R., Zuk, M., and Tregenza, T. (2001). Sexual selection and 835 speciation. Trends in Ecology \& Evolution, 16, 364-371.

836 Patterson, E. M. and Mann, J. (2011). The ecological conditions that favor tool use and 837 innovation in wild bottlenose dolphins (Tursiops sp.). PLoS ONE, 6, e22243. 
838 Patterson, E. M. (2012). Ecological and life history factors influence habitat and tool use in wild bottlenose dolphins (Tursiops sp.) (Doctoral dissertation, Georgetown University, Washington DC).

841 Patterson, E. M., Krzyszczyk, E., and Mann, J. (2015). Age-specific foraging performance and reproduction in tool-using wild bottlenose dolphins. Behavioral Ecology doi:10.1093/beheco/arv164.

844 R Development Core Team. (2015). R: A language and environment for statistical

845 computing. R Foundation for Statistical Computing, Vienna, Austria.

$846 \quad$ http://www.R-project.org/.

847 Randić, S. (2008). Spatial analysis of the distribution and home ranges of male 848 bottlenose dolphins in Shark Bay, Australia (Master's thesis, University of 849 Massachusetts Dartmouth, Dartmouth, MA).

850 Randić, S., Connor, R. C., Sherwin, W. B., and Krützen, M. (2012). A novel mammalian 851 social structure in Indo-Pacific bottlenose dolphins (Tursiops sp.): complex male 852 alliances in an open social network. Proceedings of the Royal Society B, 279, $853 \quad 3083-90$.

854 Réale, D., Boussès, P., and Chapuis, J.-L. (1996). Female-biased mortality induced by 855 male sexual harassment in a feral sheep population. Canadian Journal of $856 \quad$ Zoology, 74, 1812-1818.

857 Rodseth, L. and Novak, S. A. (2009). The political significance of gender violence. In M. 858 N. Muller and R. W. Wrangham (Eds.), Sexual Coercion in Primates and Humans 859 (pp. 292-321), Cambridge, MA, U.S.A.: Harvard University Press. 
860 Rossi, B. H., Nonacs, P., and Pitts-Singer, T. L. (2010). Sexual harassment by males 861 reduces female fecundity in the alfalfa leafcutting bee, Megachile rotundata. Animal $862 \quad$ Behaviour, 79, 165-171.

863 Sargeant, B. L., Mann, J., Berggren, P., and Krützen, M. (2005). Specialization and 864 development of beach hunting, a rare foraging behavior, by wild bottlenose 865 dolphins (Tursiops sp.). Canadian Journal of Zoology, 83, 1400-1410.

866 Sargeant, B. L., Wirsing, A. J., Heithaus, M. R., and Mann, J. (2007). Can

867 environmental heterogeneity explain individual foraging variation in wild 868 bottlenose dolphins (Tursiops sp.)? Behavioral Ecology and Sociobiology, 61, $869 \quad 679-688$.

870 Sargeant, B. L. and Mann, J. (2009). Developmental evidence for foraging traditions in 871 wild bottlenose dolphins. Animal Behaviour, 78, 715-721.

872 Schroeder, P.J. (1990). Breeding bottlenose dolphins in captivity. In S. Leatherwood 873 and R. R. Reeves (Eds.), The Bottlenose Dolphin (pp.435-446), New York, NY, $874 \quad$ U.S.A., Academic Press.

875 Scott, E., Mann, J., and Watson-Capps, J. J. (2005). Aggression in bottlenose dolphins:

876 evidence for sexual coercion, male-male competition, and female tolerance 877 through analysis of tooth-rake marks and behaviour. Behaviour, 142, 21-44.

878 Smolker, R., Richards, A., Connor, R., and Pepper, J. (1992). Sex differences in 879 patterns of association among Indian Ocean bottlenose dolphins. Behaviour, $880 \quad 123,38-69$. 
881 Smuts, B. B. and Smuts, R. (1993). Male aggression and sexual coercion of females in 882 nonhuman primates and other mammals: evidence and theoretical implications.

883 Advances in the Study of Behavior, 22, 1-63.

884 Sprogis, K. R., Raudino, H. C., Rankin, R., MacLeod, C. D., and Bejder, L. (2016).

$885 \quad$ Home range size of adult Indo-Pacific bottlenose dolphins (Tursiops aduncus) in

886 a coastal and estuarine system is habitat and sex-specific. Marine Mammal

$887 \quad$ Science, 32, 287-308.

888 Sundaresan, S. R., Fischhoff, I. R., and Rubenstein, D. (2007). Male harassment

889 influences female movements and associations in Grevy's zebra (Equus grevyi).

$890 \quad$ Behavioral Ecology, 18, 860-865.

891 Takahashi, Y. and Watanabe, M. (2010). Female reproductive success is affected by

892 selective male harassment in the damselfly Ischnura senegalensis. Animal

893 Behaviour, 79, 211-216.

894 Tsai, Y. J. and Mann, J. (2013). Dispersal, philopatry, and the role of fission-fusion

895 dynamics in bottlenose dolphins. Marine Mammal Science, 29, 261-279.

896 Tutin, C. E. G. (1979). Mating patterns and reproductive strategies in a community of

897 wild chimpanzees (Pan troglodytes schweinfurthii). Behavioral Ecology and

$898 \quad$ Sociobiology, 6 29-38.

899 Urian, K. W., Hofmann, S. and Wells, R. S. (2009). Fine-scale population structure of

900 bottlenose dolphins (Tursiops truncatus) in Tampa Bay, Florida. Marine Mammal

$901 \quad$ Science, 25, 619-638. 
902 Watson, P. J., Arnqvist, G., and Stallmann, R. R. (1998). Sexual conflict and the 903 energetic costs of mating and mate choice in water striders. The American $904 \quad$ Naturalist, 151, 46-58.

905 Watson-Capps, J. J. (2005). Female mating behavior in the context of sexual coercion 906 and female ranging behavior of bottlenose dolphins (Tursiops sp.) in Shark Bay, 907 Western Australia (Doctoral dissertation, Georgetown University, Washington, $908 \quad$ DC)

909 Watts, D. P. (1998). Coalitionary mate guarding by male chimpanzees at Ngogo, Kibale $910 \quad$ National Park, Uganda. Behavioral Ecology and Sociobiology, 44, 43-55.

911 Wearmouth, V. J., Southall, E. J., Morritt, D., Thompson, R. C., Cuthill, I. C., Partridge, 912 J. C., and Sims, D. W. (2012). Year-round sexual harassment as a behavioral 913 mediator of vertebrate population dynamics. Ecological Monographs, 82, 351 $914 \quad 366$.

915 Wells, R. (1991). The role of long-term study in understanding the social structure of a 916 bottlenose dolphin community. In K. Pryor and K. S. Norris (Eds.), Dolphin 917 Societies: Discoveries and Puzzles (pp.199-225), Berkeley, CA, U.S.A.: $918 \quad$ University of California Press.

919 Wiszniewski, J., Brown, C., and Möller, L. M. (2012). Complex patterns of male alliance 920 formation in a dolphin social network. Journal of Mammalogy, 93, 239-250.

921 Würsig, B. and Würsig, M. (1977). The photographic determination of group size, 922 composition, and stability of coastal porpoises (Tursiops truncatus). Science, $923 \quad 198,755-756$. 
Figure 1
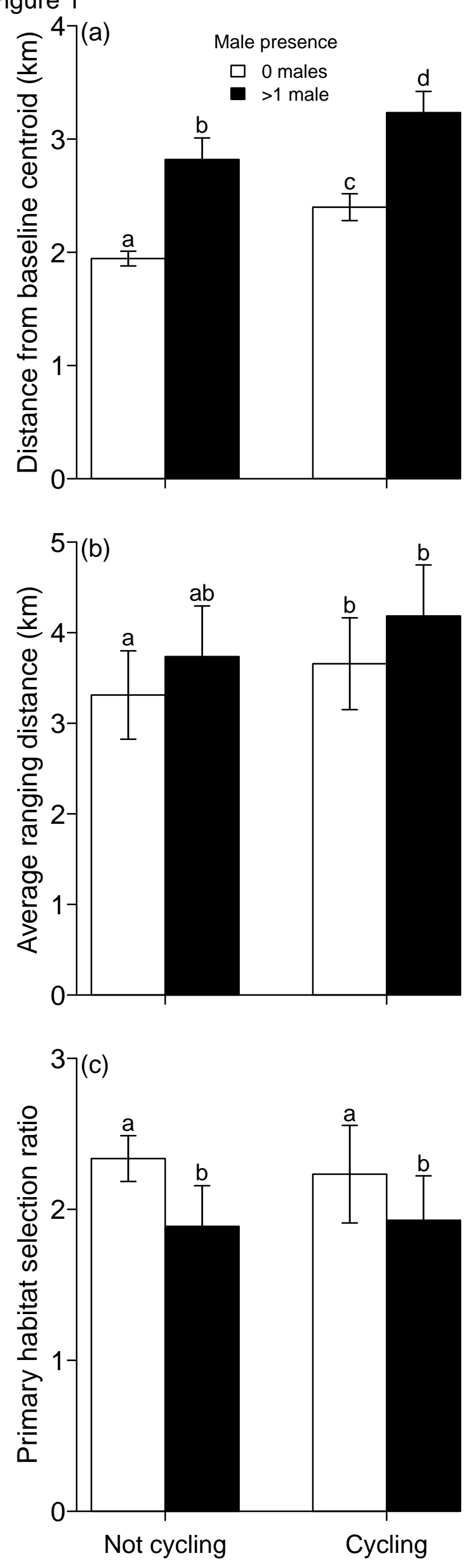

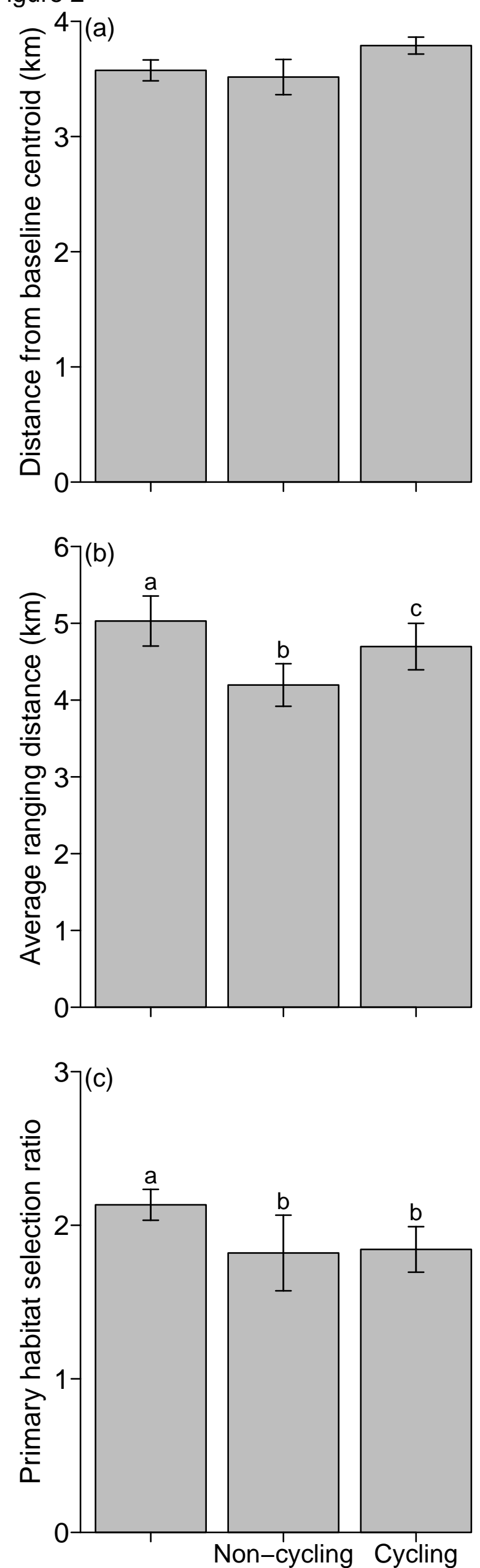

No females female(s) female(s) 